\title{
Arteriovenous malformations involving the vein of Galen
}

Vein of Galen aneurysms are rare but since the first description in $1937^{1}$ nearly 250 cases have been reported. They have been described as both aneurysms and arteriovenous malformations involving the Galenic system. The number of variants is in favour of the latter description.

\section{Anatomy}

The vein of Galen is the largest of the deep cerebral veins formed posterior to the pineal body by confluence of the two internal cerebral veins. It curves sharply upward around the splenium of the corpus collosum and drains the deep medially located veins of the diencephalon, basal ganglia, and mid brain.

Dilatation of the vein of Galen results from the force of arterial blood either directly from an artery or by way of a tributary vein or veins which receive blood from an artery. ${ }^{2}$ The dilated vein of Galen is therefore a varix associated with an arteriovenous malformation. In most cases a venous (dural) anomaly can be demonstrated downstream from the draining vein, ${ }^{3}$ and this, together with the high blood flow into the vein of Galen causes its dilatation. Hoffman et $a l^{4}$ have described four prominent angiographic patterns of Galenic arteriovenous malformations and related these to the clinical presentation treatment and outcome.

\section{PATTERN I}

Many vessels including anterior cerebral arteries, thalamic perforating arteries, and superior cerebellar arteries discharge into the vein of Galen.

PATTERN II

A single posterior choroidal artery draining into the vein of Galen.

\section{PATTERN III}

One or both posterior choroidal plus one or both anterior cerebral arteries drain directly into the Galenic system.

PATTERN IV

An angiomatous network of posterior choroidal and thalamic perforating arteries enter the vein of Galen directly.

We have recently seen a fifth pattern in which a high flow arteriovenous malformation in the right inferior frontal lobe drained via the inferior sagittal sinus and pericallosal vein into the vein of Galen (fig 1). Embryologically these patterns are explained by the persistance of fistulae between primitive pia arachnoidal arteries and plial veins which cross each other at right angles. The primitive Galenic system lies close to the primitive choroidal system so an arteriovenous malformation involving these arteries will inevitably involve the Galenic vein. ${ }^{5}$

\section{Clinical presentation}

Four clinical syndromes have been described. ${ }^{6}$ Each of these is associated with a different pattern of

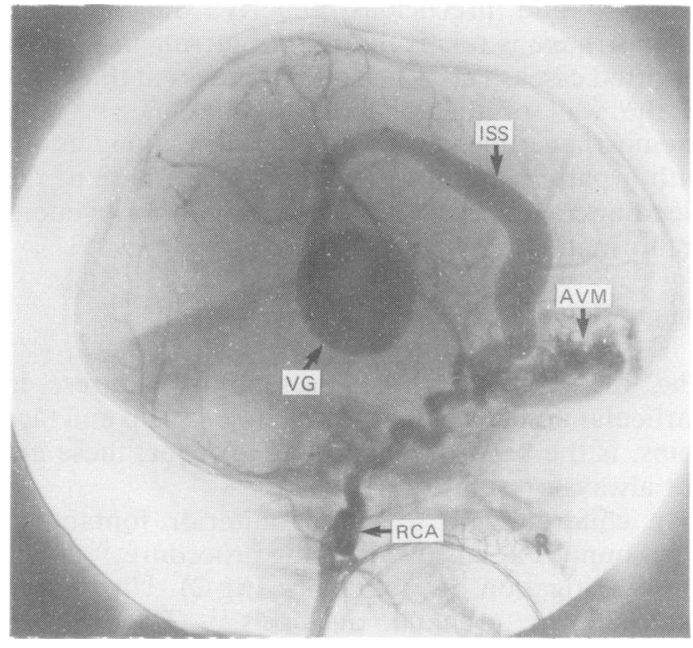

Fig 1 Right carotid arteriogram. Right frontal arteriovenous malformation ( $A V M)$ draining via the inferior sagittal sinus (ISS) into a dilated vein of Galen (VG). $R C A=$ right internal carotid artery. 
Galenic arteriovenous malformation. ${ }^{4}$ The size of the fistula dictates whether haemodynamic features predominate over local mass effect. The larger the arteriovenous shunt, the greater the haemodynamic effect and the earlier the patient presents.

Neonates presenting with severe cardiac failure and often a cranial bruit (pattern I) account for $44 \%$ of cases. These children are rarely hydrocephalic and subarachnoid haemorrhage is uncommon. The heart failure that occurs in this group is due to the size of the arteriovenous shunt which can steal $80 \%$ or more of the cardiac output, with large volumes of blood under high pressure returning to the right heart and pulmonary circulation.

Infants presenting with hydrocephalus, often a cranial bruit, occasionally epilepsy, and sometimes a progressive neurological defect caused by 'steal' phenomenon and compression of brain parenchyma by the aneurysm (patterns II and III) account for $30 \%$ of cases. The hydrocephalus is caused mainly by the mechanical effect of the dilated thick walled vein of Galen on the aqueduct of Sylvius. Communicating hydrocephalus can also occur if the venous (dural) obstruction is remote from the vein of Galen, thus affecting cerebral venous drainage and return of cerebrospinal fluid.

Children and adults presenting with headache, exercise syncope, neurological deterioration, cranial venous hypertension (distended scalp and facial veins plus epistaxis), and subarachnoid haemorrhage (pattern IV) account for $26 \%$ of cases.

More unusual presentations include various psychoses $^{78}$ and precocious puberty. Subarachnoid haemorrhage is relatively rare, occurring in $12 \%$ of reported cases. This is because of the great thickness of the wall of the dilated vein of Galen. When haemorrhage does occur it is often in young adults with a pattern IV arteriovenous malformation, the bleeding coming from the angiomatous arteriovenous malformation.

\section{Diagnosis}

The recognition of the presenting features, in particular cranial bruits and distended scalp and face veins, is the basis of diagnosis. However, these are not always present. ${ }^{9}$

In children with a patient anterior fontanelle, ultrasound is a sensitive imaging procedure,${ }^{10}$ and is the investigation of first choice (fig 2). Ultrasound has enabled prenatal diagnosis. ${ }^{11}$ The use of Doppler ultrasound allows specificity by detecting blood flow, ${ }^{10}$ and if it shows the typical features, cranial computed tomography can be avoided. If, however, the anterior fontanelle is closed or Doppler ultrasound unavailable, then contrast en-

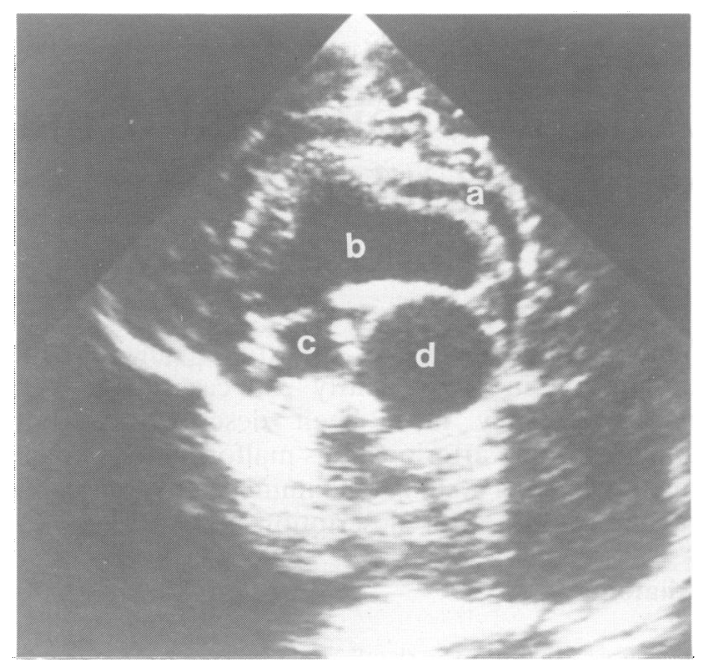

Fig 2 Sagittal ultrasound scan, midline. $a=$ Inferior sagittal sinus; $b=$ dilated lateral ventricle; $c=$ third ventricle; and $\boldsymbol{d}=$ dilated vein of Galen.

hanced cranial computed tomography should be performed. Carotid and vertebral angiography is always necessary to determine the anatomy as this will affect the surgical approach and treatment. Magnetic resonance imaging may replace angiography because of its excellent imaging ability, high resolution, and capacity to image blood flow noninvasively. ${ }^{12}$

\section{Treatment and outcome}

Supportive treatment is necessary initially. Thereafter treatment is surgical with an increasingly important contribution from interventional radiology. The overall mortality is $56 \%$. Surgical mortality is $37 \%$ with $56 \%$ serious morbidity. There have been no reports of normal survival in untreated patients.

Management depends on the angiographic pattern. In most cases it is necessary to clip the fistulous tract from the arterial side into the vein. Postoperatively the varix progressively shrinks. In children with hydrocephalus a drainage procedure is also necessary until the vein has shrunk. However, when the arteriovenous malformation is distant to the Galenic vein excision of the malformation is also necessary. It has also been reported that shunting alone can result in reduction in size of the varix. ${ }^{13}$

In neonates with pattern I Galenic arteriovenous malformations there is a $91 \%$ mortality after surgery. ${ }^{9}$ This is because the children are critically ill and in congestive cardiac failure. Myocardial infarc- 
tion is common due to appreciably reduced coronary blood flow, and previously survivors were those in whom hypotension was avoided during surgery. ${ }^{4}$ However, it is now possible to embolise the arteriovenous malformation percutaneously under radiological control using giant urco coils, ${ }^{14}$ reducing flow sufficiently to correct heart failure, and allowing elective surgery when the child is older and fitter. Where this is possible there is a significant reduction in mortality and morbidity. ${ }^{9}$

In older infants and children with pattern II, III, and IV Galenic arteriovenous malformations the mortality after surgery varies between $26 \%$ and $32 \%$. Postsurgical serious morbidity in these groups varies between $42 \%$ and $50 \%$ depending on preoperative effects of the malformation and postsurgical complications. In infants with a pattern II arteriovenous malformation and a single feeding artery, embolisation may be effective, reducing both morbidity and mortality. ${ }^{9}$

\section{Conclusion}

Arteriovenous malformations involving the vein of Galen are being seen with increasing frequency due to improved diagnostic techniques and awareness of the entity. In neonates early treatment is vital to prevent the blood supply to the cerebral parenchyma and myocardium being compromised by the flow through the malformation. In some cases this can be done effectively by embolisation. Early diagnosis and treatment in older children will similarly reduce serious morbidity and mortality. A multidisciplinary approach to investigation and management allows for satisfactory treatment in many patients.

We would like to acknowledge the advice given by Mr J Vafadis (consultant neurosurgeon) and Dr A Day (consultant paediatrician) in the preparation of this article. We would also like to acknowledge the secretarial help given by Miss D Webb.
References

1 Jaeger JR, Forbes RP, Dandy WE. Bilateral congenital cerebral arteriovenous communication aneurysm. Transactions of the American Neurology Association 1937;63:173-6.

2 'O'Brien MS, Schecter MM. Arteriovenous malformations involving the Galenic system. AJR 1970;110:50-5.

${ }^{3}$ Lasjaunias $\mathrm{P}$, Ter-Brugge K, Lopez-Ibor L, et al. The role of dural anomalies in vein of Galen aneurysms: report of six cases and review of the literature. AJNR 1987;8:185-92.

${ }^{4}$ Hoffman HJ, Chuang S, Hendrick EB, et al. Aneurysm of the vein of Galen. Experience at the Hospital For Sick Children, Toronto. J Neurosurg 1982;57:316-22.

5 Padget DH. Cranial venous system in man in reference to development, adult configuration and relation to arteries. Am J Anat 1956;98:307-55.

6 Amacher AL, Shillito J. The syndromes and surgical treatment of aneurysms of the great vein of Galen. J Neurosurg 1973;39: 89-98.

7 Aleem A, Knesevich MA. Schizophrenia like psychosis associated with vein of Galen malformation. Can J Psychiatry 1987;32:226-7.

${ }^{8}$ Ventureyra EC, Badejo A. Galenic arteriovenous malformation with precocious puberty. Surg Neurol 1984;2:45-8.

9 Johnson IH, Whittle IR, Besser M, et al. Vein of Galen malformation: diagnosis and management. Neurosurgery 1987; 20:747-58.

10 Vergesslich KA, Ponhold W, Wimmer M, et al. Diagnosis of an aneurysm of the great cerebral vein of Galen using duplex sonography. Pediatr Radiol 1986;21:377-84.

11 Vintzileos AM, Eisenfeld LI, Campbell WA, et al. Prenatal ultrasonic diagnosis of arteriovenous malformation of the vein of Galen. Am J Perinatol 1986;3:209-11.

12 Roosen N, Schirmer M, Lins E, et al. MRI of an aneurysm of the vein of Galen. AJNR 1986;7:733-5.

${ }^{13}$ Pun KK, Yu YL, Huang CY, et al. Ventriculo-peritoneal shunting of acute hydrocephalus in vein of Galen malformation. Clin Exp Neurol 1987;23:209-12.

14 McCord FB, Shields MD, McNeil A, et al. Cerebral arteriovenous malformation in a neonate. Treatment by embolisation. Arch Dis Child 1987;62:1273-5.

A A Nicholson, M D Hourihan, and C HAYWARD Department of Radiology, University Hospital of Wales, Heath Park, Cardiff CF4 $4 X N$ 